\title{
Influence of Compression Coil Geometry in Electromagnetic Forming Using Experimental and Finite Element Method
}

\section{Manoj Soni ( $\sim$ soni44@gmail.com )}

Council of Scientific and Industrial Research(CSIR)-Advanced Materials and Processes Research

\section{Meraj Ahmed}

Council of Scientific and Industrial Research(CSIR)-Advanced Materials and Processes Research

\section{Sanjay Kumar Panthi}

Council of Scientific and Industrial Research(CSIR)-Advanced Materials and Processes Research

\section{Surendra Kumar}

Academy of Scientific and Innovative Research (AcSIR), Ghaziabad-201002, India Institute (AMPRI), Bhopal-462026, India

\section{Khushwant Singh Gavel}

Council of Scientific and Industrial Research(CSIR)-Advanced Materials and Processes Research

\section{Research Article}

Keywords: Electromagnetic forming, Compression coil, Inductance, Energy level, Current amplitude. Frequency, Process parameters, Finite element simulation

Posted Date: March 11th, 2021

DOl: https://doi.org/10.21203/rs.3.rs-213808/v1

License: (c) (i) This work is licensed under a Creative Commons Attribution 4.0 International License. Read Full License

Version of Record: A version of this preprint was published at The International Journal of Advanced Manufacturing Technology on August 13th, 2021. See the published version at https://doi.org/10.1007/s00170-021-07832-7. 


\section{Abstract}

Electromagnetic forming process is a high velocity forming technique which is widely used in automotive and aerospace sectors for forming and joining metallic sheet/tubes. The geometrical structure of compression coil have significant effect on the performance of the system in terms of current output and deformation of workpiece. The present work aims to analyse the effect of structural parameters of compression coil like cross-section of turns $(X)$, pitch circular diameter (PCD) and effective turn (n) using both experimental and numerical simulation. A bitter compression coil of variable geometrical structure have been considered to see the effect of its parameters by deforming an AA6061 tube experimentally. Parameters like magnetic field, velocity, Lorentz force, displacement and stress are difficult to measure experimentally but have significant indication on performance of the coil in EMF. The trends of numerically predicated parameters find good agreement with experimental deformation value of tube. The Finite element analysis is carried out to correlate deformation results. The results indicate that $\mathrm{n}$ have higher significant in performance of compression coil as compared to $X$ and PCD of coil.

\section{Introduction}

In the present scenario demand for light-weight and high specific strength materials are continuously increasing mainly in automobile and aerospace sector in order to save cost and increase fuel efficiency. Joining of similar and dissimilar light weight metals and forming of sheet metal are sometimes challenging due to various associated problems. These problems can be addressed with the help of high velocity joining and forming technique like electromagnetic forming (EMF), electrohydraulic forming (EHF) etc. EMF is a high energy rate forming technique that is widely used for joining of similar/dissimilar metal parts, cutting, crimping and sheet metal forming of the parts. It can be utilized for both sheet and tubular types of parts. Some of the major advantages of EMF process are enhanced formability, reduced wrinkling and controlled springback effect, better strain distribution in sheet metal forming, improvement in dimensional accuracy in forming, elimination of heat-affected zone in welding and its environment friendly nature etc. [1-4]. This technique can be used in almost all sectors like automobile, aerospace, medical, nuclear, air conditioning and home appliance industries [4]. Depending on application of the process, generally three types of coil are used. Compression coil is used to compress a tubular geometry in inward direction to either achieve a desired shape of the tube or joining it to another tube on rod placed inside the tube in overlapped condition. Similarly, expansion coil is used for expansion of tube. Flat forming coil is used for sheet metal forming of flat workpiece. All these coils are of spiral helical in nature. So coil is the core parts of the tooling in EMF process and its geometrical structure plays important role in improving the performance of EMF process.

In the past, several researchers have used finite element simulation and experimental methods for studying various aspects like coil design, effect of process parameters etc. in electromagnetic forming. A few initial work in EMF is discussed to review the evolution of the process. One of the early work reported in the area reveals preliminary design of expansion of coil and its effect on various parameters such as frequency of discharge, velocity, discharge current and pressure acting on the work-piece [5]. Further work 
by Lal et al. [6] proposed a theoretical analysis of current in a typical EMF circuit considering coil parameters such as inductance, resistance and frequency. After a brief pause in research work in the area for about a decade (in 70s and 80s), there was renewed interest because of availability of high speed computational facility and requirement of light weight material in various sectors. Some of the work related to processing of material and various aspect of effect of coil design in EMF is discussed in the following paragraph.

Takatsu et al. [7] developed the analytical model to calculate of magnetic force and eddy current induced in workpiece using spiral flat coil in electromagnetic sheet metal forming process. Murata et al. [8] presented a tube forming method using a tapered coil and called it tube streaming method. Effect of various parameters such as energy discharged by capacitor bank, length of tube and position of tube on deformation and profile of streaming has been examined. Min et al. [9] developed a FEM model and analysed the formation of wrinkles on the tube wall in electromagnetic tube compression. The effect of different shapes of the mandrel on the tube compression was studied and it was proposed the usage of mandrel can reduce wrinkles in electromagnetic forming process. A FEM model proposed by Lee et al. [10] analysed pressure distribution on the coil and workpiece. Effect of elements types on the error in FEM simulation was studied. It proposed that decrease in size and increase in number of elements reduce error but it increases computational time. Xiaohui Cui et al. [11] used two different coupling methods for improvement of current pulse in FE simulation. First current pulse gives better accuracy in case loose coupling method whereas second pulse give good accuracy in case of sequential coupling method. It was also reported that the effect of increase in frequency results in improved deformation of sheet. Zhang et al. [12] studied the effect of skin depth and magnetic pressure on the workpiece deformation. Work carried out by Lee et al. [13] gives relation between magnetic pressure and tube length. It established the optimum length of tube that gives maximum deformation. It was argue that the size of tube length should be equal to the coil length to obtain maximum pressure on the workpiece. Fenton et al. [14] proposed a FEM model for electromagnetic sheet metal forming process using Arbitrary LagrangianEulerian Code called CALE. The program was written in C programming language. Zang et al. [15] Proposed $\mathrm{E}$ shaped coil and its effect on the magnetic field developed across the coil. The gap of the coil is also optimized. It was argued that the performance of $E$ shaped coil is better than other general coils. Chengxiang et al. [16] welded the dissimilar materials (i.e. Al-Cu and Al-Mg) through electromagnetic joining and found the effect of magnetic field, force and induce current distribution on the welded region using FE simulation and compared the result with experimental one. Microstructural analysis was carried out across the joint region. Meriched et al. [17] proposed a flat coil design in electromagnetic sheet metal forming process. Oliveira et al. [18] developed numerical simulation model for studying forming of aluminium alloy sheet through EMF method and studied variation of strain distribution along the sample and its formability using forming limit diagram. Azab et al. [19] worked on various FEM model for electromagnetic forming analysis and a comparative study was carried out amongst them. Numerous challenges involved in FEM analysis of electromagnetic forming are discussed. Karch et al. [20] developed a FEM model and determined the different parameters that affect the EMF process. The parameters are air gap, frequency, skin depth and joule heating loss. Stiemer et al. [21] developed an 
algorithm for calculation of electromagnetic field. Numerical simulation was carried out to study the effect of change in the shape of the workpiece and found that the magnetic field is very sensitive to change in shape of workpiece. Kore et al. [22] established a technique for joining of Al-Mg sheet metal joining using EMF process. Parameter like skin depth, energy and standard thickness of sheet etc. are optimized to obtain good quality of joining. Bartels et al. [23] compared two different simulation algorithms for modelling an electromagnetic forming process and found that the loose coupled model can be only used for the relatively fast deformation and small displacement. It was proposed that sequential coupled model are more accurate and should be used for large deformation problems. Haiping et al. [24] analysed the effect of current frequency on the deformation of AA-3003 tube using numerical simulation and compared the effect of different frequencies on deformation. Optimum frequency was determined to get the largest deformation. Mamalis et al. [25] proposed a FEM model for compression coil with stepped field shaper and flat coil for deforming a tube and sheet metal parts. Effect of charging voltage, magnetic flux and Lorentz force in electromagnetic forming process was analysed. Shrivastava et al. [26] optimized stand of distance, energy and thickness of tube in electromagnetic forming and validated results of FE simulation with experimental one. Various parameters like magnetic field, velocity, Lorentz force, displacement and velocity associated with EMF process was also calculated using FE simulation and co-related with experimental results. Ahmed et al. [27] proposed concept of uniform and non-uniform coil for flat sheet metal forming. Parameters like magnetic field, Lorentz force etc. was analysed for both the coil and it was established the non-uniform coil provides improved electromagnetic force for forming sheet metal. Arezoodar et al. [28] developed a FEM model for investigation effect of different parameters such as material property, peak current etc. on inward tube deformation. It was established that material property can affect the depth of deformation. Li et al. [29] proposed a FEM model for analysing electromagnetic forming of low conducting materials using a high conducting driver material and investigated the distribution of magnetic force variation. Cao et al. [30] investigated the effect of current frequency in electromagnetic sheet metal forming process using finite element method. The study showed that frequency varies according to the capacitance of the system and it affects displacement or deformation of the material. Frequency and skin depth have been optimized to obtain maximum deformation. X. Zeng et al (2020) [31] proposed a new technique to deform the aluminium alloy sheet using a single copper strip by imposing inverse current into the copper strip and workpiece. The FE simulation of deformation was also carried out and results were validated with experiments. Dond et al. [32] investigated the effect of field shaper on the electromagnetic field distribution in EMF. Experimental and numerical simulation was carried out and found that the usage of field shaper can increase field intensity by 5.6 times. It was also found that the distribution of magnetic pressure and flux density would be more uniform with the help of a field shaper. Savadkoohian et al. [33] analysed the effect of various parameters such as tube thickness, die entrance radius, discharge current and energy on wrinkling and bead depth on aluminium AA7075-T6 tube compression in electromagnetic forming process and found that the bead depth and die entrance radius have more effective on controlling wrinkling as compared to other parameters. 
From above literature review, it can be seen that a very negligible work has been carried out on establishing the effect of bitter coil structural geometry on electromagnetic forming of Al alloy tubes using finite element method. It is known fact the understanding the design of bitter coil structure is an important aspect in electromagnetic forming process for its improved performance. There are many parameters like magnetic field, Lorentz force, velocity, stress and strain distribution that are very difficult to obtain and analyse experimentally. Various aspect of bitter coil like pitch circular diameter (PCD), turn cross section (X) and effective turns ( $\mathrm{n}$ ) have huge effect on output current pulse of the system and thereby effecting forming and joining of tubes of various materials. The present work studies the effect of variation in coil geometry structure on deformation and its correlation with various FE calculated parameters with experimental results. Four different combination of $P C D, X, n$ of coil are considered to analyse its effect on the process parameters such as magnetic field, deformation, velocity, Lorentz force, displacement and effective stress has been established. It mainly focuses on the effect of various numerically calculated parameters due to coil geometry variation on deformation of aluminium alloy AA6061 tube to understand processing of materials in EMF. FEM results have been validated with experimental results in terms of maximum deformation of the tube. Commercially available LS-Dyna software is used for FEM analysis of tube deformation in electromagnetic forming.

\section{Materials And Methods}

\subsection{Materials}

Effect of variation in coil geometry and its correlation with FEM calculated parameters are validated by experimentally deforming an aluminium alloy tube. Aluminium alloys is generally used in aerospace and automobile application due to light-weight and high specific strength. Aluminium alloy AA6061 has been used to perform the experimental work in the present work. The tubes are annealed at $350^{\circ} \mathrm{C}$ with holding time of two hours. The mechanical properties of AA6061 in terms of flow curve of A6061 at both quasistatic and high strain rate are shown in Fig. 1. The same flow curve has been used in finite element analysis. Copper is used for fabrication of coil and field shaper. Chemical composition and mechanical properties of AA6061 alloy are listed in Table 1. The mechanical properties of AA6061 and copper are given in Table 3.

\subsection{Methods}

\subsubsection{Experimental setup}

A $40 \mathrm{~kJ}$ electromagnetic manufacturing (EMM) machine is used for forming of Al tube in present work. A schematic line diagram of the electromagnetic forming setup is shown in Fig. $\mathbf{2}$ and picture of same is shown in Fig. 3. It mainly consists of four parts namely control console, capacitor bank rack, the programmable logic controller (PLC) rack and worktable (with discharge coil). The energy is stored in four capacitor banks and each capacitor bank has four capacitors of $56 \mu \mathrm{F}$ capacity. So that the total capacitance of the machine is $224 \mu \mathrm{F}$. The control console is a human machine interface (HMI) that is 
used to select charging parameters such as the number of capacitor banks and charging voltage. So it is also used to controls, visualize and select these parameters. The coil and other tooling is fastened on the worktable, and the workpiece is placed inside the coil. Six turn bitter coil with field shaper is used in the present work. Details of the coil geometry is discussed in the next section. The output current pulse and associated parameters are measured with the Rogowski coil and digital storage oscilloscope of Tektronix make (model TPS 2024B). The capacitor banks are charged by high voltage DC supply from power supply rack and it stores power in the form of static charge. The stored energy is instantly released through a coil fixed on worktable. The discharge current produces a strong dynamic magnetic field around the coil (primary current). The change in flux of magnetic field induces an opposing effect in the nearby placed workpiece and an opposite direction current (secondary current) flows through the workpiece which produces opposing magnetic field. These two opposing magnetic field generates repulsive Lorentz force that accelerate the flyer workpiece to achieve desired shape. Charging of capacitors banks takes $5 \mathrm{~s}$ to $15 \mathrm{~s}$ depending on the rate of charging, applied energy /voltage, whereas it discharges through the coil in a very short time of 50-150 $\mu \mathrm{s}$.

\subsubsection{Methodology}

In the present work, coil geometry is varied with fixed geometry of field shaper and workpiece (tubular AA6061). The dimensions of coil along with level of energy used for experimental work is listed in Table 3. The workpiece is $90 \mathrm{~mm}$ long with $24 \mathrm{~mm}$ outer diameter and $3 \mathrm{~mm}$ thickness. The effect of coil geometry variation on numerically calculated parameters and subsequently on the deformation of workpiece is correlated. Change in coil geometry such as PCD, cross section of turn (X) and effective turn (n) (as listed in Table 3 ) has effect on various parameters of electromagnetic forming process such as magnetic field, Lorentz force, velocity and displacement. The constant gap of $1 \mathrm{~mm}$ have been maintained between the coil and the field shaper. The same gap is also maintained between the field shaper and workpiece. Experiments are performed at only one energy/voltage levels using two capacitor banks but FE simulation of both $18 \mathrm{kV}$ and $16 \mathrm{kV}$ conditions are carried out (as mentioned in Table 3 ).

Fig. 4 shows schematic actual picture of coil and field shaper.

Analysis of EMF process to study the effect of coil geometry has been carried out using LS-Dyna finite element software. FEM model of the setup (coil, field shaper and tube) have been built up as per actual dimension. The model is meshed with 3D solid hexahedral element. Size of elements is $5 \mathrm{~mm}$ and it has been kept constant for both coil and field shaper. There is variation in number of elements for the coil because of variation in coil geometry as per Table 4. Coil A, B, C and D have 22386, 20696, 18240 and 16720 elements respectively. Field shaper has 5808 number of elements. Material properties as given in Table 2 and Fig. 1 have been assigned. The load is applied across coil in terms of current pulse using set segment feature of LS-DYNA. Experimentally determined current pulse corresponding to the level of voltage used in experiments are applied. Details of the current pulse obtained in experiments are discussed in next section. EFM model of the setup is shown in Fig 5. Boundary condition have been applied according to actual fastening condition used in experiments. 


\section{Results And Discussion}

Results of FEM simulation and corresponding experiments work have been discussed in this section. Comparative analysis (both numerical and experimental) of deformation of tube due to variation in coil geometry is carried out. Parameters which are difficult to determine experimentally are estimated numerically and correlated with experimental deformation. The value of these numerically estimated parameters are taken from outer layer of element/node of tubular workpiece located at the opposite to the slit of the field shaper. Result of current pulse and comparison of deformation of tube through experimental and FE simulation corresponding to all coils at both $18 \mathrm{vkv}$ and $16 \mathrm{vkv}$ of energy levels are listed in Table 4. Peak value of current and frequency shows that coil B has highest current and there is no change in frequency for the same coil even at different energy levels. So frequency does not depend on energy of the system. The complete pulse of current for all coils at both energy level is shown in Fig 6 . At both levels of energy coil B given maximum peak value of current i.e. $140 \mathrm{kA}$ and $155 \mathrm{kA}$ at $16 \mathrm{kV}$ and $18 \mathrm{kV}$ respectively. It is obvious that highest current deforms the tube to the highest value as compared to lower current peak achieved by other coils. The same can be verified from both experimentally measured and numerically estimated final OD of tube as shown in Table 4. Coil B reduces the OD to $15.62 \mathrm{~mm}$ from $24 \mathrm{~mm}$ in both experimental and FE simulation. This is the highest deformation achieve amongst all coils at both energy level. Experiments are conducted at $18 \mathrm{kV}$ energy level only. The comparison of experimental and numerical deformation shows very good agreement as the difference in the value is below $6 \%$. The comparison of peak value of current as shown in Fig 6 shows that highest peak current is achieved by coil B followed by coil C, A and D. The comparison of coil geometry shows that coil B has highest value of PCD amongst all coils and lower effective turns as compared to $A$. Both $A$ and $B$ has same value of OD with just $3 \mathrm{~mm}$ difference in ID. So it can be concluded that $B$ has optimal condition combination of effective turns and turn cross section. So both the value of PCD, turn cross section and effective turns plays important role in output current pulse. The turn cross section of coil $B$ is lower than A. This indicates that the resistance of the $B$ must be high as compared to $A$ leading to high current but the results show opposite trends. It can be argued that the effective turns is more dominant factor as it influences the inductance of the coil significant. It is known fact that the value of inductance have more influence on discharge current pulse as well as frequency. Similar finding can be co-related by comparing effective turns in coil $A$ and $B$. Coil $B$ have lower number of effective turn that leads to higher value of current magnitude and frequency of current as compared to A. The comparison of values of PCD of coil A and $D$ shows that they have same value and it indicates that PCD hold minimal effect on the output performance of coil when compared to effective turn. Similarly value of deformation in terms of OD of tube also shows same trend and it is plotted in Fig 7. Highest deformation is achieved by B coil at both energy level. Results of FE simulation in terms of contour of displacement at both level of energy for all the coils are shown in Fig 8 . The experimentally deformed tube sample at $18 \mathrm{kV}$ is also shown in the figure. It shows very good agreement when experimentally deformed tube is compared with numerical one. It can also be verified pictorially that coil $B$ deformed to maximum value as compared to other coils. Thus the effect of coil geometry have been analysed by comparing deformation and pulse of the current. 
The associated parameters ( magnetic field, Lorentz force, velocity, displacement and stress ) of electromagnetic forming which is difficult to measure/ determined experimentally is estimated numerically and variation of their values for different coils are correlated. Data obtained through FE simulation can be represented in two way: one only peak value and another variation of the parameter during whole duration of deformation. Maximum value of all numerically estimated parameter listed in Table 5. Comparative analysis of peak value and complete deformation duration of these parameters are shown in Fig. 9 to 12. Variation of magnetic field at the centre of tube (opposite to the slit of field shaper) as calculated by FE simulation for al coils are shown in Fig 9. Both peak value as well as its variation during deformation shows same trend as shown by corresponding peak value of current. Coil $B$ has highest value of magnetic field i.e.; $15 \mathrm{~T}$ followed by $\mathrm{C}, \mathrm{A}$ and $\mathrm{D}$ at both levels of energy. Similar trends can be seen for Lorentz force and velocity as seen in Fig. 10 and 11.The comparison of magnetic field to the nearest highest value which is produced by coil $\mathrm{C}$ shows an approximate variation of $1 \mathrm{~T}$. There is a difference of approximately $1.5 \mathrm{~T}$ when effect of energy i.e. $16 \mathrm{kV}$ and $18 \mathrm{kV}$ is evaluated for all the coils. The peak value of velocity is $308 \mathrm{~m} / \mathrm{s}$ and $234 \mathrm{~m} / \mathrm{s}$ for coil B at $18 \mathrm{kV}$ and $16 \mathrm{kV}$ respectively. This value is significantly high when compared to next level of three value i.e.; $252 \mathrm{~m} / \mathrm{s}$ and $190 \mathrm{~m} / \mathrm{s}$ for coil C. The importance of this magnitude of variation of velocity can be very significant when critical value of impact velocity is important to achieve joining of two metal. The importance of the same is discussed by kore et al. [37]. The comparison of maximum stress induced due to different coil reveals similar trend i.e. highest stress is induced by coil B as compared to all other coil as shown in Fig. 12. So for all energy bank, selecting a suitable coil geometry is very crucial for workpiece deformation in electromagnetic forming for any application.

\section{Conclusions}

A study on the effect of variation in coil geometry on the deformation of the tube in electromagnetic forming process by experimental and numerical simulation is carried out in the present work. The numerical results are presented in terms of the magnetic field, velocity, Lorentz force, displacement and effective stress. The numerical simulation results are verified with experimental in terms of deformation of tube and a very good agreement was observed. The finding of the present work is summarized below:

1. There is significant effect of PCD, turn cross-section and effective turns on deformation of tube.

2. Effective turns hold higher significance as compare to both PCD and turn cross-section of a compression coil. It can be argued that effective turns influence the inductance of the coil and turn cross section influence the resistance. It infers that the value of inductance has very important role in coil design and its performance in terms of output of the system or the deformation of workpiece/job.

3. The comparative analysis of tube deformation through experiments and simulation shows good agreement. Other parameters like magnetic field, velocity, Lorentz force, displacement and effective stress have been predicated numerically to correlate the findings. The experimental findings are in good agreement with numerically calculated trends of these parameters. Coil B shows maximum 
deformation experimentally and corresponding numerically predicated values of magnetic field, velocity, Lorentz force, displacement and effective stress are also highest amongst all the coils. So the FE analysis can be used to predict the performance of the coil by varying its effective number of turns, PCD and turn cross section before it is fabricated.

\section{Declarations}

\section{Acknowledgements}

The authors would like to thanks Director, CSIR-AMPRI Bhopal for providing the facilities and CSIR New Delhi for support to perform this work.

\section{References}

1. Seth M, Vohnout VJ, Daehn GS (2005) Formability of steel sheet in high velocity impact. Mater. Process. Technol. 168(3): 390-400. DOI:10.1016/j.jmatprotec.2004.08.032.

2. Golovashchenko SF (2007) Material formability and coil design in electromagnetic forming. Mater. Eng. Perform. 16: 314-320. DOI: 10.1007/s11665-007-9058-7.

3. Kalpakjian S, Sekar K, Vijai, Schmid SR (2014) Manufacturing engineering and technology. Pearson.

4. Psyk V, Risch D, Kinsey BL, Tekkaya AE, Kleiner M (2011) Electromagnetic forming-a review. Mater. Process. Technol. 211: 787-829. DOI: 10.1016/j.jmatprotec.2010.12.012.

5. Baines K, Duncan J, Johnson W (1965) Electromagnetic metal forming. Instn. Mech. Engrs. 180(1): 93-110. DOI: 10.1243/PIME_PROC_1965_180_013_02.

6. Lal G, Hillier M (1968) The electrodynamics of electromagnetic forming. J. Mech. Sci. 10(6): 491-500. DOI: 10.1016/0020-7403 (68)90030-1.

7. Takatsu N, KATO M, Sato K, Tobe T (1988) High-speed forming of metal sheets by electromagnetic force. JSME international journal. Ser. 3, Vibration, control engineering, engineering for industry. 31(1): 142-148. DOI: 1299/jsmec1988.31.142.

8. Murata M, Suzuki H (1990) Profile control in tube flaring by electromagnetic forming. Mater. Process. Technol. 22(1): 75-90. DOI: 10.1016/0924-0136(90)90143-I.

9. Min DK, Kim DW (1993) A finite-element analysis of the electromagnetic tube-compression J. Mater. Process. Technol. 38(1-2): 29-40. DOI: 10.1016/0924-0136 (93)90183-7.

10. Lee SH, Lee DN A (1994) finite element analysis of electromagnetic forming for tube expansion. J. Eng. Mater. Technol. ASME (United States). 116(2): DOI: 1115/1.2904281.

11. Cui X, Mo J, Li J, Huang L, Zhu Y, Li Z, Zhong K (2013) Effect of second current pulse and different algorithms on simulation accuracy for electromagnetic sheet forming. J. Adv. Manuf. Technol. 68, 1137-1146. DOI: 10.1007/s00170-013-4906-0.

12. Zhang H, Murata M, Suzuki $H$ (1995) Effects of various working conditions on tube bulging by electromagnetic forming. Mater. Process. Technol. 48(1-4): 113-121. DOI:10.1016/0924-0136 
(94)01640-M.

13. Lee SH, Lee DN (1996) Estimation of the magnetic pressure in tube expansion by electromagnetic forming. Mater. Process. Technol. 57(3-4): 311-315. DOI: 10.1016/0924-0136 (95)02086-1.

14. Fenton GK, Daehn GS (1998) Modeling of electromagnetically formed sheet metal. Mater. Process. Technol. 75(1-3): 6-16. DOI: 10.1016/S0924-0136(97)00287-2.

15. Zhang, H, Yang Z, Ren L (2019) Experimental investigation on structure parameters of E-shaped coil in magnetic pulse welding. Manuf. Processes. 34(15): 1701-1709. DOI:

10.1080/10426914.2019.1689263.

16. Li C, Zhou Y, Shi X, Liao Z, Du J, Shen T, Yao C (2020) Magnetic field edge-effect affecting joint macro-morphology in sheet electromagnetic pulse welding. Manuf. Processes. 1-11. DOI: 10.1080/10426914.2020.1758332.

17. Meriched A, Féliachi M, Mohellebi $H(2000)$ Electromagnetic forming of thin metal sheets. IEEE Trans. Magn. 36(4): 1808-1811. DOI: 1109/20.877796.

18. Oliveira D, Worswick M (2003) Electromagnetic forming of aluminium alloy sheet. Journal de Physique IV (Proceedings). EDP sciences 293-298. DOI: 1051/jp4:20020709.

19. El-Azab A, Garnich M, Kapoor A (2003) Modeling of the electromagnetic forming of sheet metals: state-of-the-art and future needs. Mater. Process. Technol. 142(3): 744-754. DOI: 10.1016/S09240136(03)00615-0.

20. Karch C, Roll K (2005) Transient simulation of electromagnetic forming of aluminium tubes. Advanced Materials Research. Trans Tech Publ.: 639-648. DOI:4028/www.scientific.net/AMR.68.639 .

21. Stiemer M, Unger J, Svendsen B, Blum H (2006) Algorithmic formulation and numerical implementation of coupled electromagnetic-inelastic continuum models for electromagnetic metal forming. J. Numer. Methods Eng. 68(13): 1301-1328. DOI: 10.1002/nme.1738.

22. Kore SD, Imbert J, Worswick M, Zhou Y (2009) Electromagnetic impact welding of Mg to Al sheets. Technol. Weld. Joining. 14(6): 549-553. DOI: 10.1179/136217109X449201.

23. Bartels G, Schätzing W, Scheibe HP, Leone, M (2009) Comparison of two different simulation algorithms for the electromagnetic tube compression. J. Mater. Form. 2(1): 693. DOI: 10.1007/s12289-009-0620-8.

24. Haiping Y, Chunfeng L, Jianghua D (2009) Sequential coupling simulation for electromagneticmechanical tube compression by finite element analysis. Mater. Process. Technol. 209(2): 707-713. DOI: 10.1016/j.jmatprotec.2008.02.061.

25. Mamalis A, Manolakos D, Kladas A, Koumoutsos A (2006) Electromagnetic forming tools and processing conditions: numerical simulation. Mater. Process. Technol. 21(4): 411-423. DOI: 10.1080/10426910500411785.

26. Shrivastava A, Telang A, Jha A, Ahmed M (2019) Experimental and numerical study on the influence of process parameters in electromagnetic compression of AA6061 tube. Manuf. Processes.: 1-12. DOI:10.1080/10426914.2019.1655156. 
27. Ahmed M, Panthi S, Ramakrishnan N, Jha A, Yegneswaran A, Dasgupta R, Ahmed S (2011) Alternative flat coil design for electromagnetic forming using FEM. Transactions of Nonferrous Metals Society of China. 21(3): 618-625. DOI:1016/S1003-6326(11)60759-0.

28. Arezoodar AF, Haratmeh HE, Farzin M (2012) Numerical and experimental investigation of inward tube electromagnetic forming-electromagnetic study. Advanced Materials Research. Trans Tech Publ: 6710-6716. DOI:4028/www.scientific.net/AMR.383-390.6710.

29. Li F, Mo J, Zhou H, Fang Y (2013) 3D Numerical simulation method of electromagnetic forming for low conductive metals with a driver. J. Adv. Manuf. Technol. 64(9-12): 1575-1585. DOI: 10.1007/s00170-012-4124-1.

30. Cao Q, Han X, Lai Z, Zhang B, Zhou Z, Qiu L, Li L (2013) Effects of current frequency on electromagnetic sheet metal forming process. IEEE Trans. Appl. Supercond. 24(3): 1-4. DOI: 1109/TASC.2013.2279886.

31. Zeng X, Meng Z, Liu W, Huang S, Zhou S, Lin Y (2020) Electromagnetic forming of aluminum alloy strip by imposing inverse current instead of inducing eddy current. J. Adv. Manuf. Technol. 111 (2020) 3481-3488. DOI: 10.1007/s00170-020-06356-w.

32. Dond S, Kulkarni M, Kumar S, Saroj P,Sharma A (2015) Magnetic field enhancement using field shaper for electromagnetic welding system. IEEE Applied Electromagnetics Conference (AEMC). IEEE: 1-2. DOI: 1109/AEMC.2015.7509219.

33. Savadkoohian H, Arezoodar AF, Arezoo B (2017) Analytical and experimental study of wrinkling in electromagnetic tube compression. J. Adv. Manuf. Technol. 93(1-4): 901-914. DOI: DOI 10.1007/s00170-017-0571-z.

34. Guo Y, Wen Q, Horstemeyer M (2005) An internal state variable plasticity-based approach to determine dynamic loading history effects on material property in manufacturing processes. J. Mech. Sci. 47: 1423-1441. DOI: 10.1016/j.jjmecsci.2005.04.015.

35. Johnson GR, Cook WH (1985) Fracture characteristics of three metals subjected to various strains, strain rates, temperatures and pressures. Fract. Mech. 21: 31-48.

36. Shang J, Hatkevich S, Wilkerson L (2012) Comparison between experimental and numerical results of electromagnetic tube expansion. 12th International Ls-Dyna Users Conference Detroit, USA: 1-10.

37. Kore SD, Dhanesh P, and Kulkarni SV (2010) Numerical modeling of electromagnetic welding. J. Appl. Electromagnet Mech. 32(1): 1-19. DOI:10.3233/JAE-2010-1062.

\section{Tables}

Table 1. Chemical composition of AA6061 [26, 34]

\begin{tabular}{|lllllll|}
\hline Elements & $\mathrm{Cu}$ & $\mathrm{Fe}$ & $\mathrm{Si}$ & $\mathrm{Mg}$ & $\mathrm{Mn}$ & $\mathrm{Al}$ \\
\hline Weight (\%) & 0.183 & 0.569 & 0.73 & 0.507 & 0.0924 & Remaining \\
\hline
\end{tabular}


Table 2. Mechanical properties of Aluminium alloy AA6061 and OFHC copper $[34,35]$

\begin{tabular}{|llll|}
\hline Material & Density $\left(\mathrm{kg} / \mathrm{m}^{3}\right)$ & Poisson's ratio & Young Modulus $(\mathrm{GPa})$ \\
\hline AA-6061 & 2700 & 0.33 & 69 \\
\hline OFHC $(\mathrm{Cu})$ & 8960 & 0.34 & 124 \\
\hline
\end{tabular}

Table 3. Details of coil and geometry at which experiments carried out

\begin{tabular}{|llllll|}
\hline Coil & $\begin{array}{l}\text { Area of } \\
\text { cross } \\
\text { section } \\
(\mathbf{X})\end{array}$ & $\begin{array}{l}\text { Pitch circular } \\
\text { diameter (PCD) }\end{array}$ & $\begin{array}{l}\text { Effective } \\
\text { turns (n) }\end{array}$ & $\begin{array}{l}\text { Energy (E)/Voltage } \\
(\mathrm{kV}) \text { (Double bank) }\end{array}$ & $\begin{array}{l}\text { Energy (E)/Voltage } \\
(\mathrm{kV}) \text { (Double bank) }\end{array}$ \\
\hline A & $8 \times 64.5$ & 155.5 & 4.23 & $18 \mathrm{kV}$ & $16 \mathrm{kV}$ \\
\hline B & $8 \times 63$ & 157 & 4.16 & $18 \mathrm{kV}$ & $16 \mathrm{kV}$ \\
\hline C & $8 \times 58$ & 152 & 4.16 & $18 \mathrm{kV}$ & $16 \mathrm{kV}$ \\
\hline D & $8 \times 54.5$ & 155.5 & 4.16 & $18 \mathrm{kV}$ & $16 \mathrm{kV}$ \\
\hline
\end{tabular}

Table 4. Details of experimental and simulation using different coil at double bank $18 \mathrm{kV}$ and $16 \mathrm{kV}$ 


\begin{tabular}{|c|c|c|c|c|c|c|}
\hline \multirow{2}{*}{$\begin{array}{l}\text { Coil } \\
\text { (Noltage } \\
\text { in kV) }\end{array}$} & \multirow{2}{*}{$\begin{array}{l}\text { Current } \\
\text { (kA) }\end{array}$} & \multirow{2}{*}{$\begin{array}{l}\text { Frequency } \\
\text { (f) }\end{array}$} & \multicolumn{2}{|l|}{ Deformation } & \multirow{2}{*}{$\begin{array}{l}\text { \% difference } \\
\text { between } \\
\text { experiments } \\
\text { and simulation }\end{array}$} & \multirow[t]{2}{*}{ Remark } \\
\hline & & & Experimental & Simulation & & \\
\hline $\begin{array}{l}A \\
(18 \mathrm{kV})\end{array}$ & 140 & 11.6 & 16.4 & 16.8 & $2.38 \%$ & $\begin{array}{l}\text { Both } \\
\text { experiment } \\
\text { and } \\
\text { simulation } \\
\text { carried out }\end{array}$ \\
\hline $\begin{array}{l}A \\
(16 \mathrm{kV})\end{array}$ & 132 & 11.6 & - & 18.8 & - & $\begin{array}{l}\text { Only } \\
\text { simulation } \\
\text { carried out }\end{array}$ \\
\hline $\begin{array}{l}\text { B } \\
(18 \mathrm{kV})\end{array}$ & 155 & 12.5 & 15.07 & 15.62 & $3.52 \%$ & $\begin{array}{l}\text { Both } \\
\text { experiment } \\
\text { and } \\
\text { simulation } \\
\text { carried out }\end{array}$ \\
\hline $\begin{array}{l}\text { B } \\
(16 \mathrm{kV})\end{array}$ & 140 & 12.5 & - & 17.96 & - & $\begin{array}{l}\text { Only } \\
\text { simulation } \\
\text { carried out }\end{array}$ \\
\hline $\begin{array}{l}\text { C } \\
(18 \mathrm{kV})\end{array}$ & 144 & 11.6 & 16.3 & 16.72 & $2.51 \%$ & $\begin{array}{l}\text { Both } \\
\text { experiment } \\
\text { and } \\
\text { simulation } \\
\text { carried out }\end{array}$ \\
\hline $\begin{array}{l}\text { C } \\
(16 \mathrm{kV})\end{array}$ & 132 & 11.6 & - & 18.72 & - & $\begin{array}{l}\text { Only } \\
\text { simulation } \\
\text { carried out }\end{array}$ \\
\hline $\begin{array}{l}\text { D } \\
(18 \mathrm{kV})\end{array}$ & 136 & 10.6 & 17.03 & 18.08 & $5.80 \%$ & $\begin{array}{l}\text { Both } \\
\text { experiment } \\
\text { and } \\
\text { simulation } \\
\text { carried out }\end{array}$ \\
\hline $\begin{array}{l}\text { D } \\
(16 \mathrm{kV})\end{array}$ & 120 & 10.6 & - & 20.5 & - & $\begin{array}{l}\text { Only } \\
\text { simulation } \\
\text { carried out }\end{array}$ \\
\hline
\end{tabular}

Table 5. Maximum value of process parameters in electromagnetic forming of AA6061 tube using different coils at $18 \mathrm{kV}$ and $16 \mathrm{kV}$ 


\begin{tabular}{|llllll|}
\hline $\begin{array}{l}\text { Coil (Voltage in } \\
\text { kV) }\end{array}$ & $\begin{array}{l}\text { Magnetic } \\
\text { field } \\
\text { (Tesla) }\end{array}$ & $\begin{array}{l}\text { Lorentz force } \\
\left(\mathrm{GN} / \mathrm{m}^{3}\right)\end{array}$ & $\begin{array}{l}\text { Velocity } \\
(\mathrm{m} / \mathbf{s})\end{array}$ & $\begin{array}{l}\text { Displacement } \\
(\mathrm{mm})\end{array}$ & Stress \\
\hline A (18 kV) & 13.9 & 231 & 250 & 3.6 & 413 \\
\hline A (16 kV) & 12.5 & 189 & 183 & 2.6 & 401 \\
\hline B (18 kV) & 15 & 275 & 308 & 4.19 & 424 \\
\hline B (16 kV) & 13.4 & 222 & 234 & 3.02 & 409 \\
\hline C (18 kV) & 13.9 & 229 & 252 & 3.64 & 415 \\
\hline C (16 kV) & 12.7 & 192 & 190 & 2.64 & 403 \\
\hline D (18 kV) & 13.7 & 207 & 191 & 2.96 & 404 \\
\hline D (16 kV) & 12.1 & 156 & 119 & 1.75 & 387 \\
\hline
\end{tabular}

Figures 


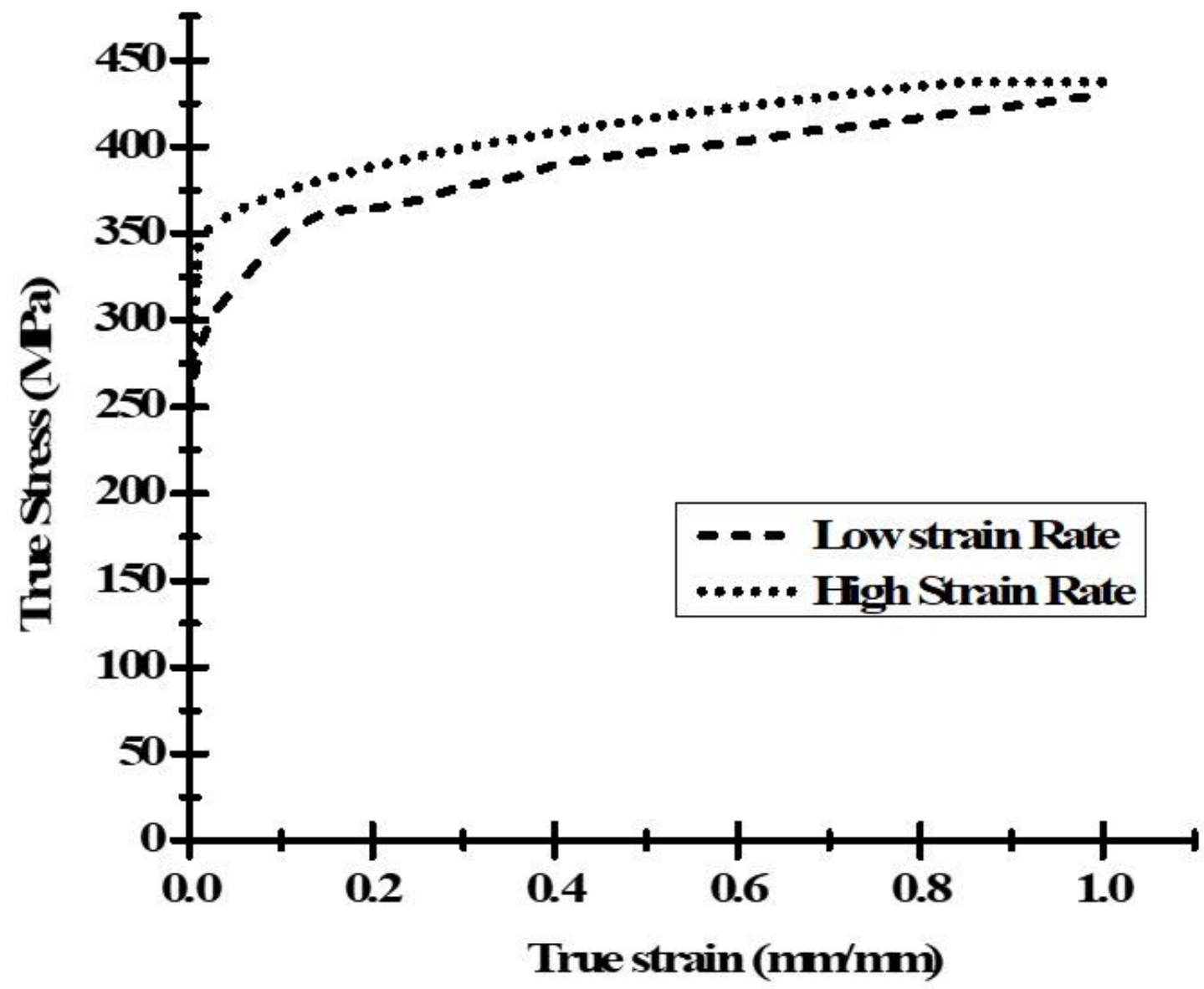

Figure 1

True stress strain curve of Aluminium alloy AA6061 at quasi static and high strain rate $[34,36]$ 


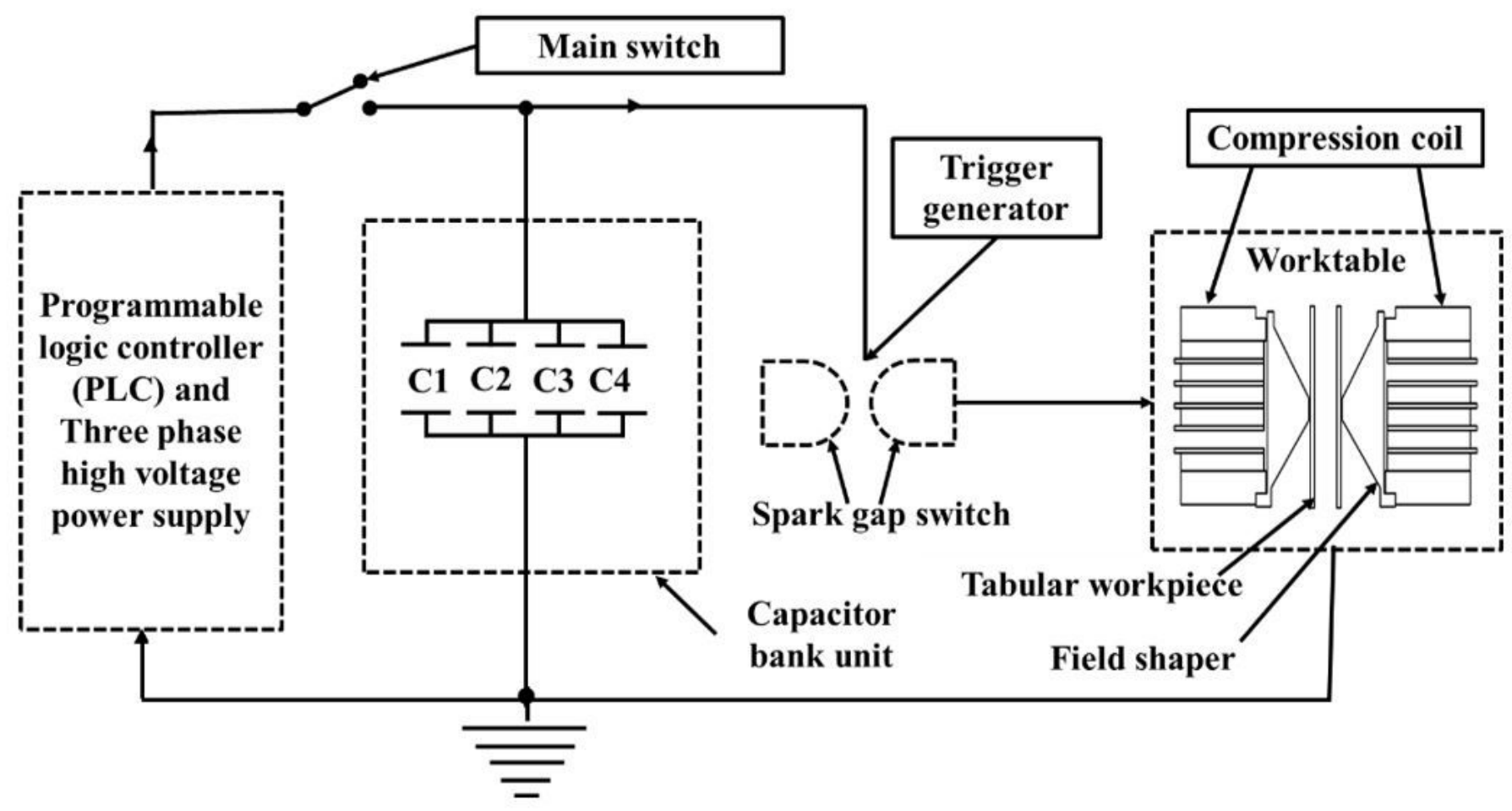

Figure 2

Schematic line diagram of circuit of electromagnetic forming machine
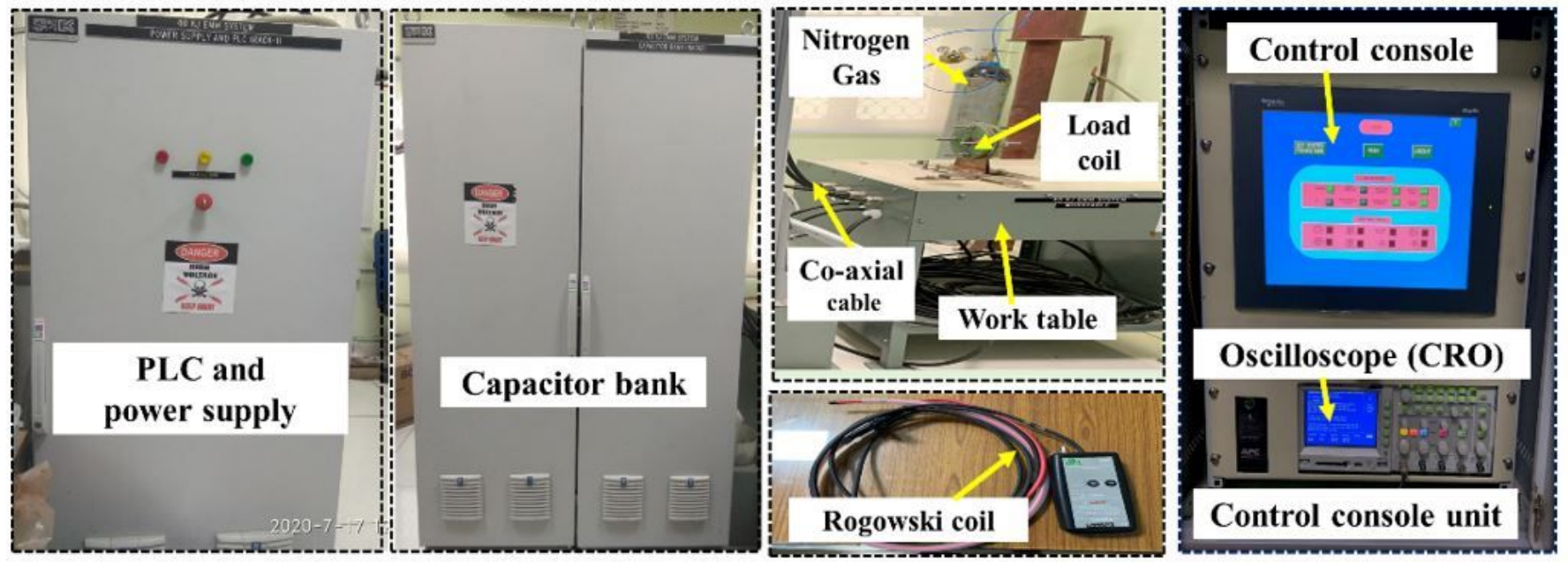

Figure 3

Different components of electromagnetic forming (EMF) system used in experiments 

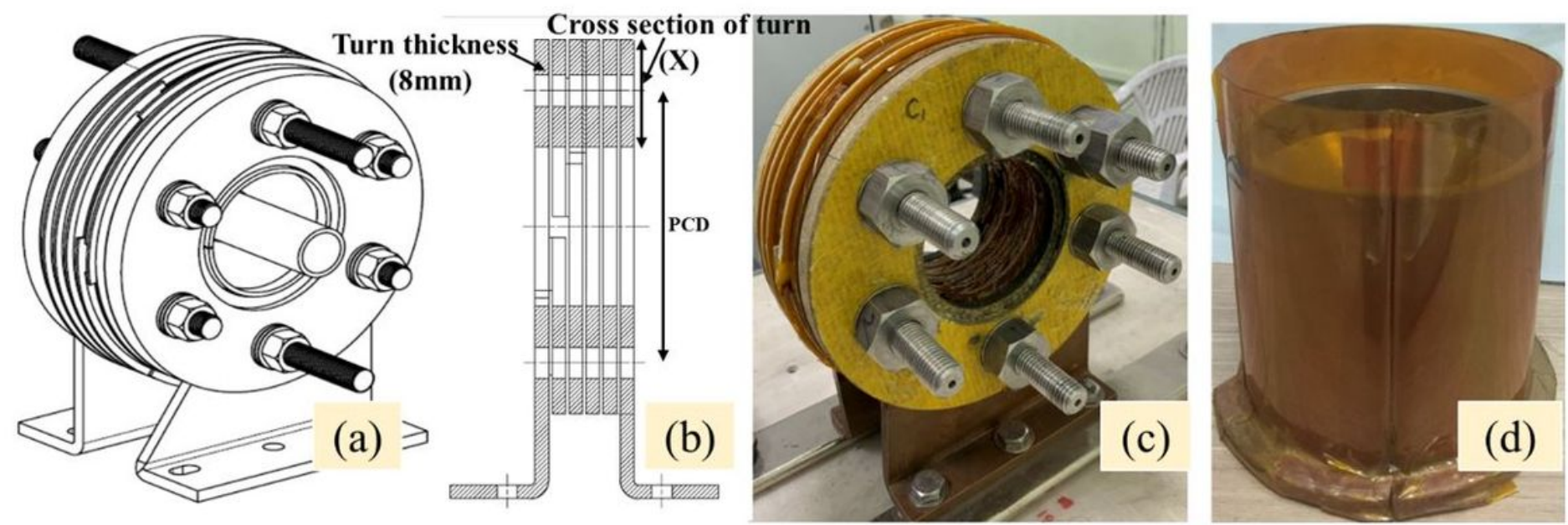

Figure 4

(a) Isometric view (b) Sectional view of coil (c) Actual picture of coil and (d) Field shaper used in the experiments

(a)

(b)

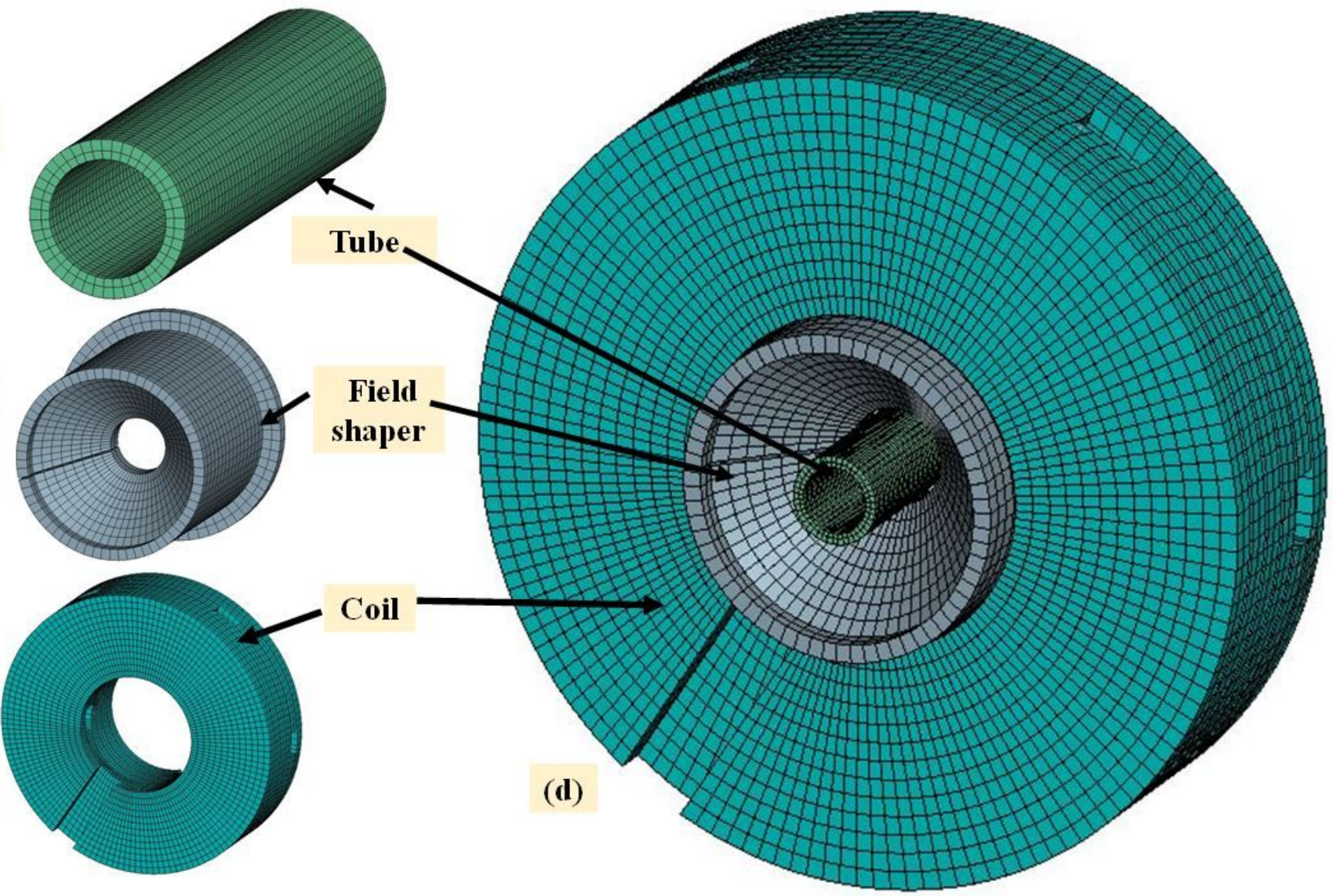

Figure 5

FEM Model of (a) workpiece, (b) field shaper, (c) coil and (d) all parts in assembled condition 

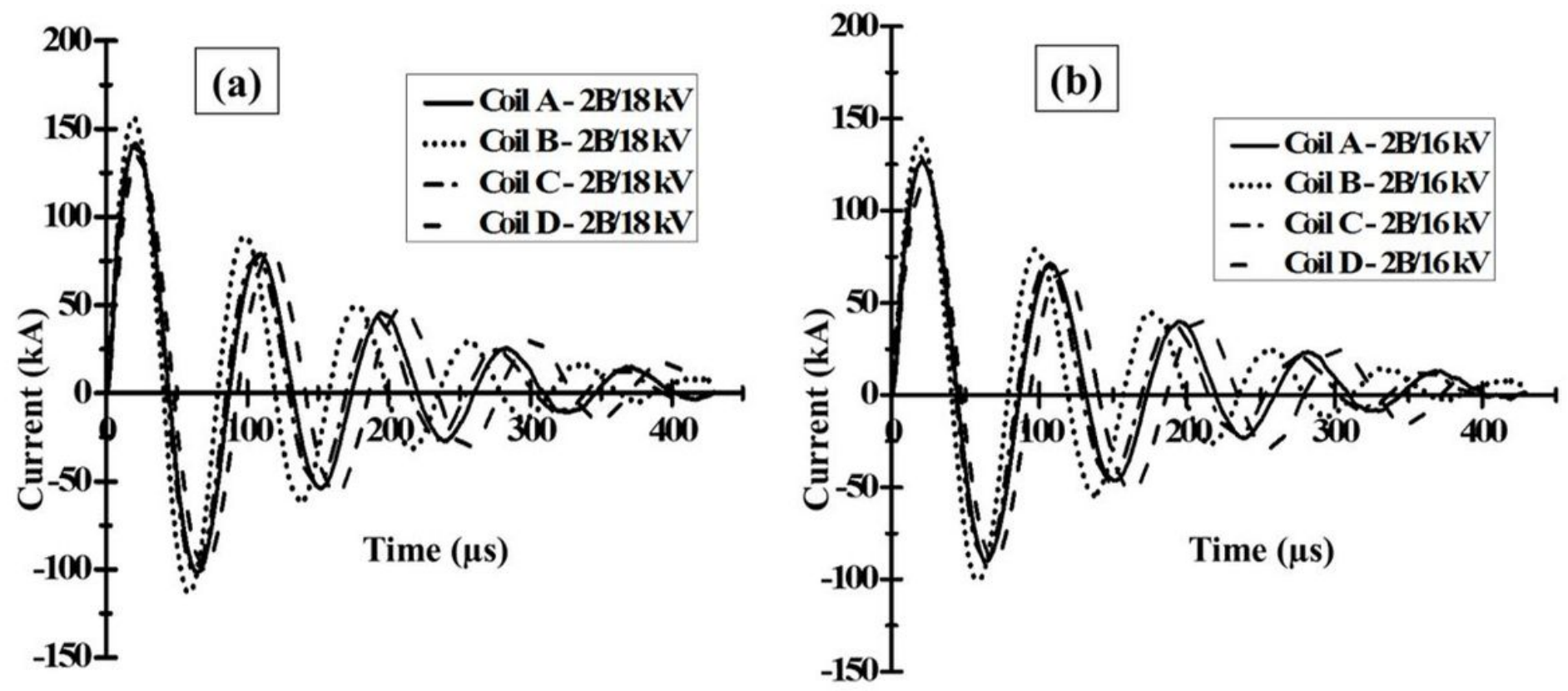

Figure 6

Effect of different coil geometry on current pulse at double bank at (a) $18 \mathrm{kV}$ and (b) $16 \mathrm{kV}$
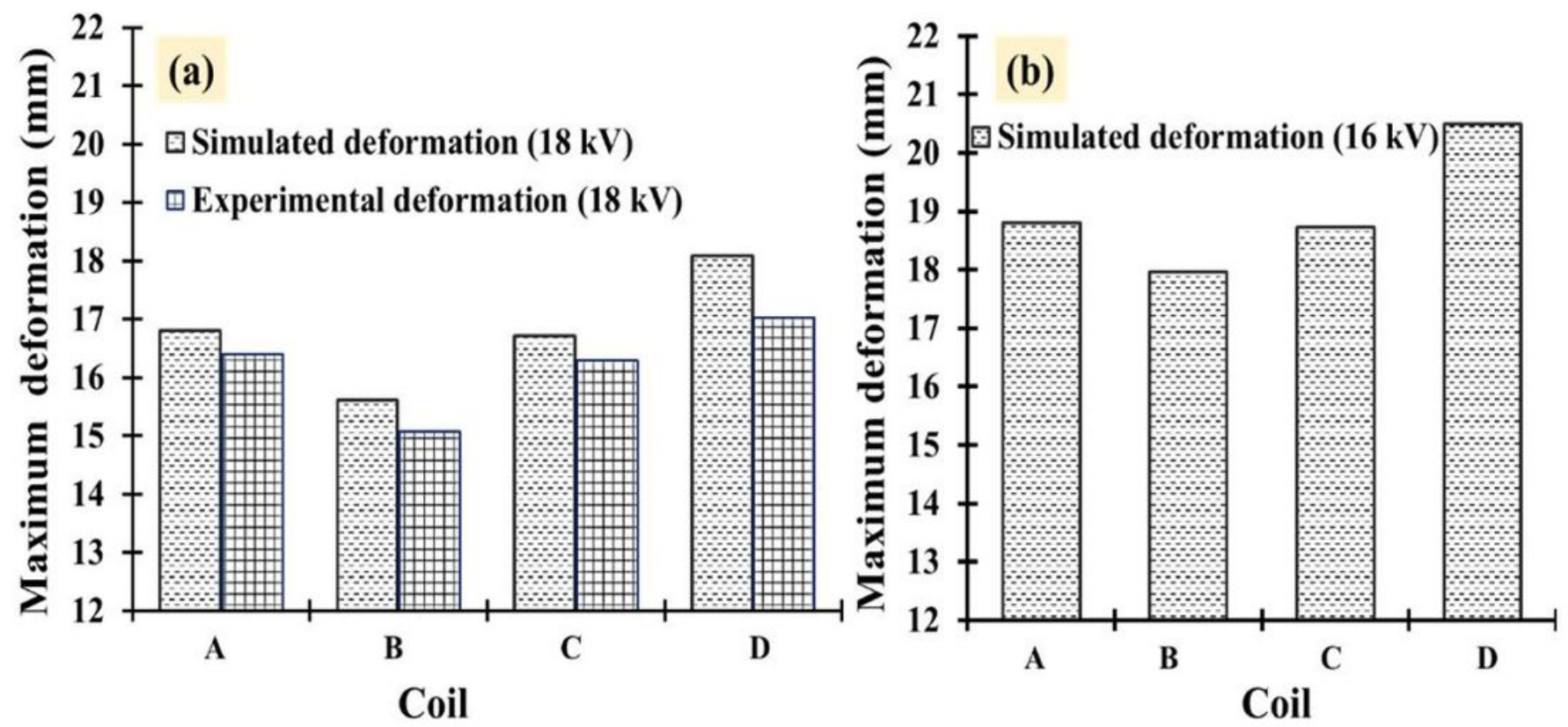

Figure 7

Variation maximum deformation of AA6061 tube using different coils (a) using double bank at $18 \mathrm{kV}$ (Both experimental and simulation) and (b) using double bank at $16 \mathrm{kV}$ (only simulation) 


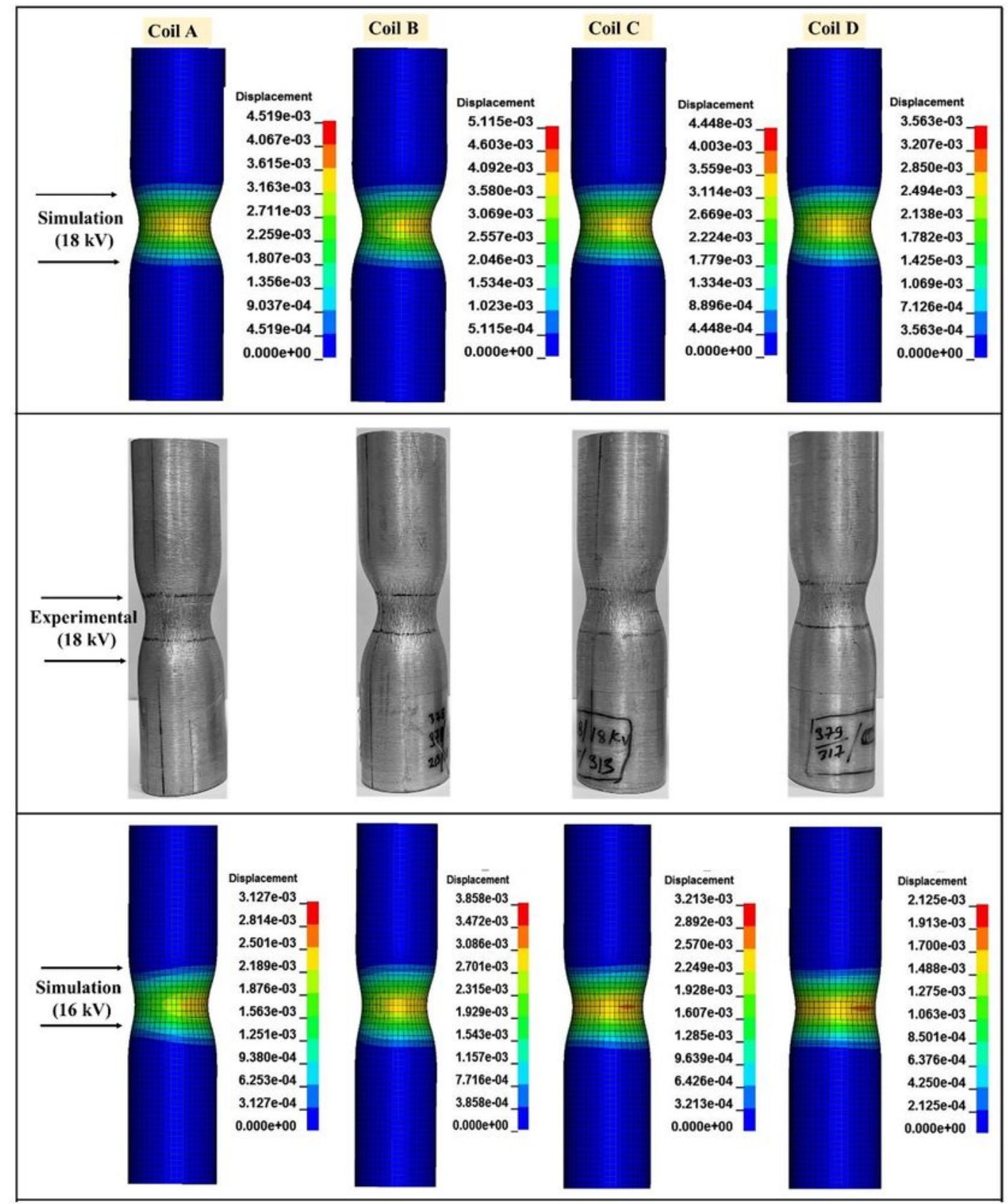

\section{Figure 8}

Deformation of tube using different coil at $18 \mathrm{kV}$ (experimental and simulation) and $16 \mathrm{kV}$ only simulation 

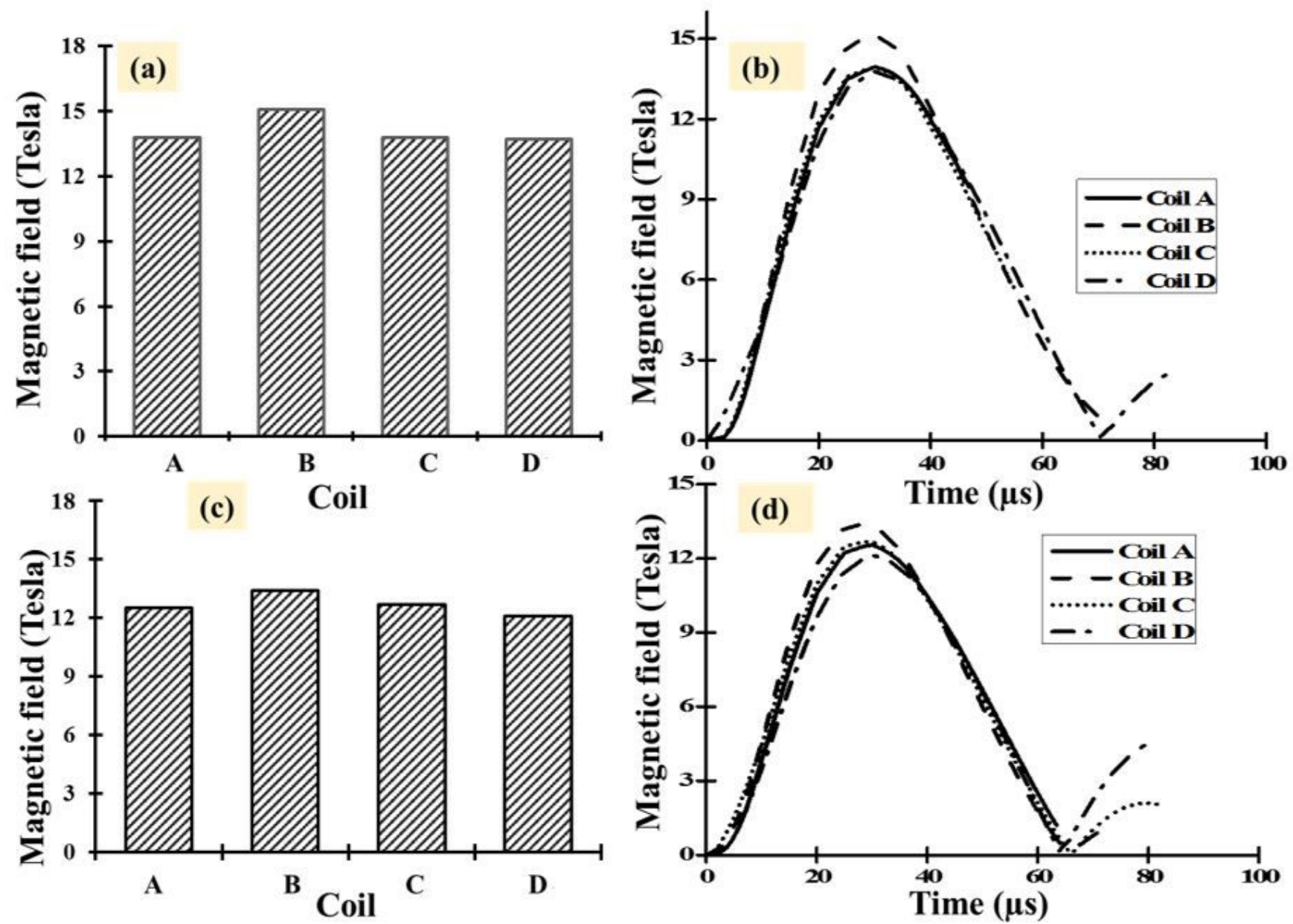

Figure 9

Variation of magnetic field using different coils at $18 \mathrm{kV}(\mathrm{a}, \mathrm{b})$ and $16 \mathrm{kV}(\mathrm{c}, \mathrm{d})$ 

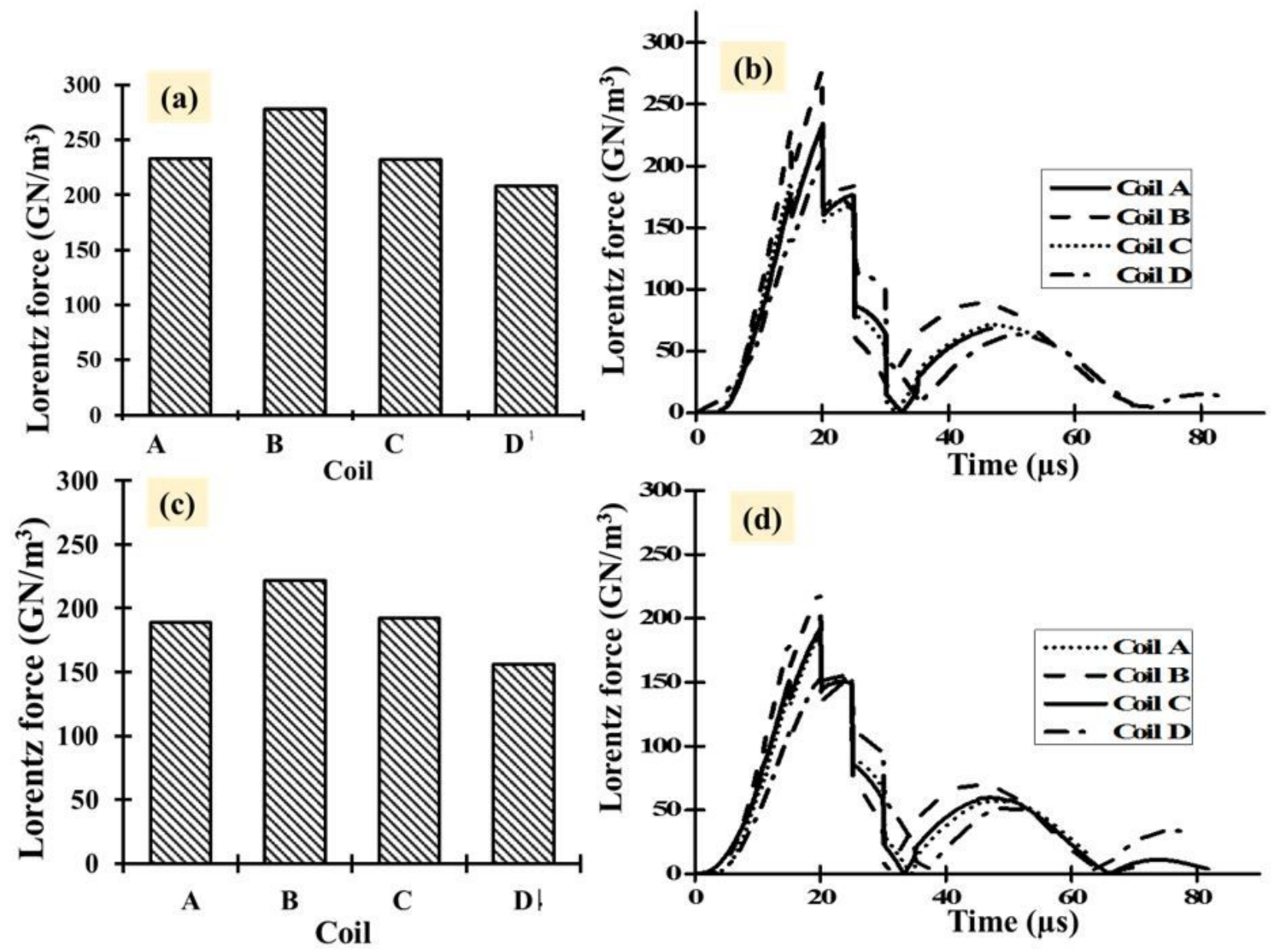

Figure 10

Influence of different coil geometry on Lorentz force at double bank $18 \mathrm{kV}(\mathrm{a}, \mathrm{b})$ and 16kV (c, d) 

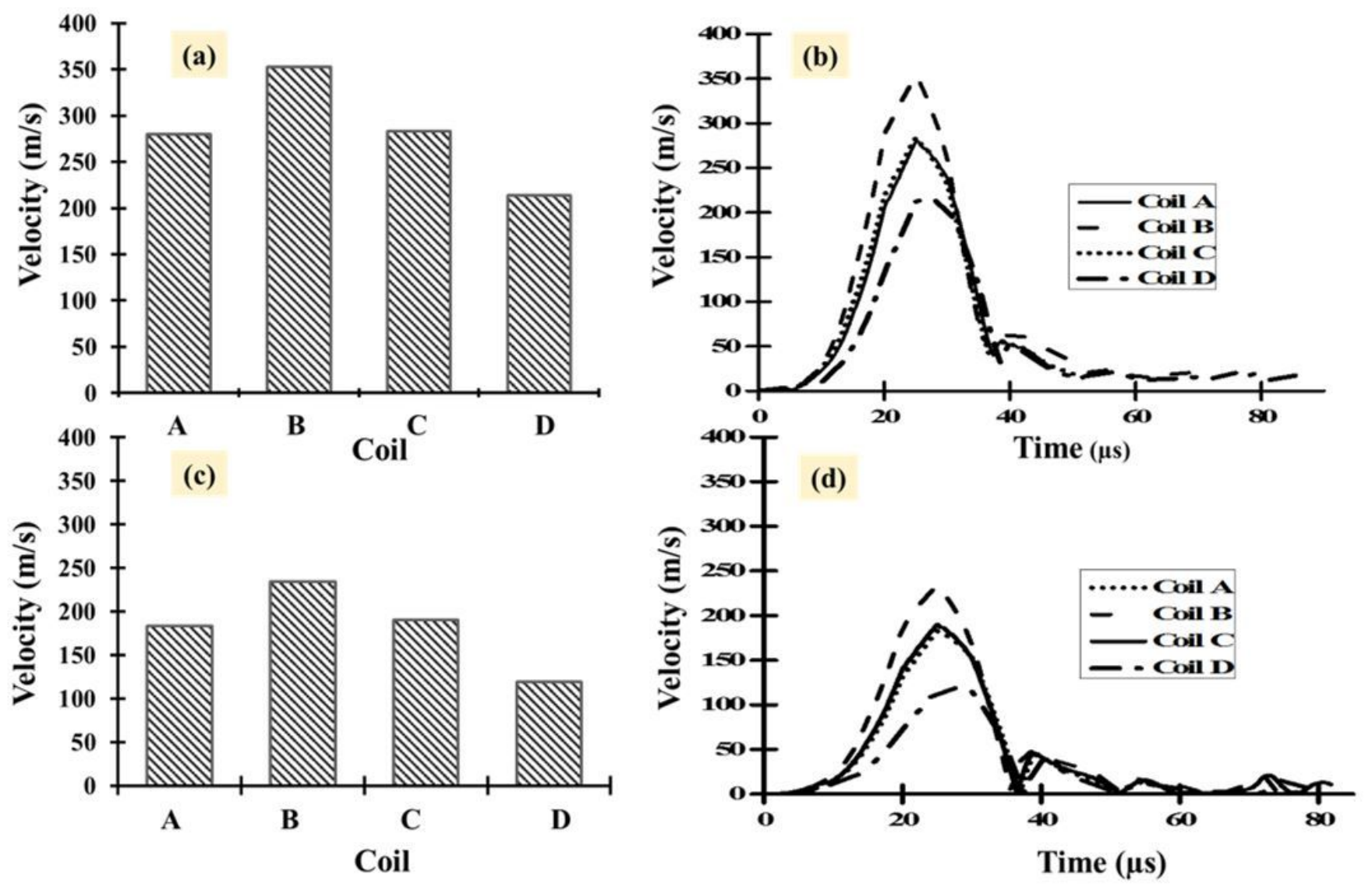

Figure 11

Variation of velocity using different coils at $18 \mathrm{kV}(a, b)$ and $16 \mathrm{kV}(c, d)$ 


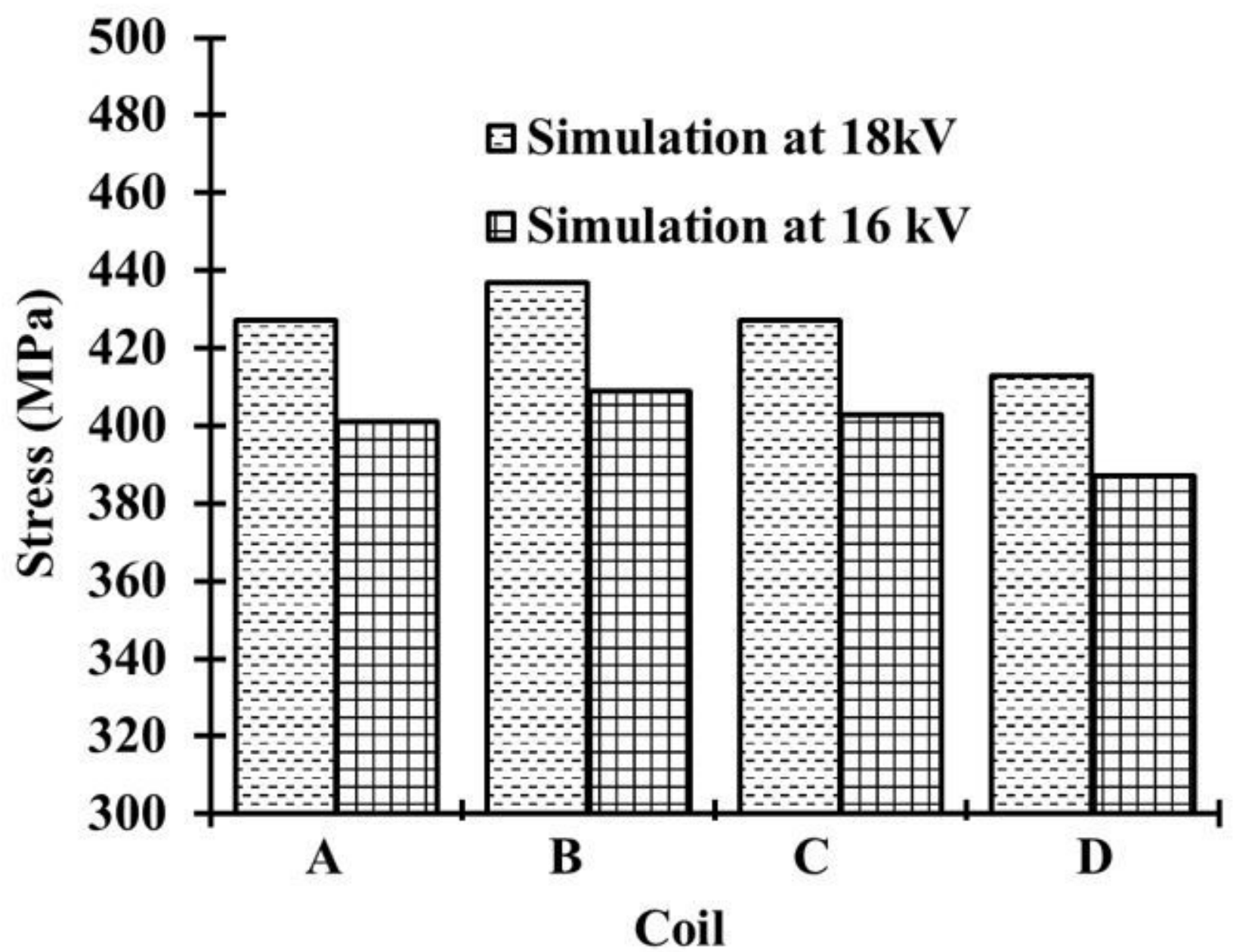

Figure 12

Maximum value of stress after the deformation of AA-6061 tube when used the different types of coil condition at double bank $18 \mathrm{kV}$ and $16 \mathrm{kV}$ 